century and partly because he lived at a time when many of the older ideas on the treatment of disease were undergoing change. Moreover, his style of writing is somewhat clearer than that of some of his contemporaries as the following translation from Bauderon shows: "The Humours may bee inflamed without putrefaction and cause a continual Feaver, which hath but one Fit, and that longer than a Diary, whose four times are taken from its essence and from the matter, viz. (the fervid blood hurting our actions) whether it be homotonous, epacmastical, or paracmastical." Bauderon's prescription for "a cooling Glister" is more distinct: "Take of violet leaves, Mallows, Lettice, Gourds, Burrage, each a handful, Prunes sixteen, of the four great cold Seeds each two drams, red Poppyflowers and Roses, each a small handful, boyle them in Whey or Water to a pint, streine it, and dissolve of Diaprune simple, and Cassia newly drawn, each six drams, honey of Violets and oyl of Water-Lillies, each an ounce and half, or so much of oyle of Cammomel if it be not exquisite, and make a Glister." You will notice that practically all the substances used for the glister are aromatic bodies, apart from any other properties which they may possess. The preface to Bauderon's book, "The Expert Physician," from which these extracts were taken is perhaps worth quoting as an example of how it is possible to err on the side of modesty: "Such emunct nostrils as shall snuffe at it are like those my Author speaks of that will swound at the smel of a Rose; suburban wits that breathe best in the worst Air ; or like some unclean Creatures that thrive best in standing Pools; but I leave them and commend the ingenious to the work itself, methodical, facil, and perspicuous enough to benefit the meanest capacity, yet satisfie the highest; read and be convinced.

The practice of bleeding in fevers seems to have been favoured from the earliest times, though Galen recommends that it should not be practised in patients ander 14 years of age " because children's bodies be soone resolved from outward heate, and therefore by voyding of blood they should bee greatly weakened." Some authorities have considered certain days in the year unlucky for bleeding-more especially the first day of May, the last day of September, and the last day of April, and there are also many other criteria which render the patient unsuitable for bleeding. Such for instance is "subtile sensitiveness of the stomack's mouth, which is called the heart-string," according to the School of Salerno in the seventeenth century, "for of such blood-letting swounding followeth lightly." In fact, the dangers which attended it in the old days seem to have been very considerable and Celsus states that "although blood-letting is the easiest of all operations to one practised in it, nevertheless to the unskilful it is exceedingly difficult, for the vein is in apposition with arteries and these last with nerves. If, therefore, the lancet should touch the nerve convulsions ensue and miserably destroy the man."

Such, gentlemen, is a short sketch of the treatment of fevers up to the end of the seventeenth century, and I leave it for you to judge how far this treatment has improved since the time of Hippocrates.

I feel that I cannot do better than conclude with a quotation from this the earliest physician whose writings have come down to us-a quotation which will remain true for all time: "Life is short, and the Art long; the occasion fleeting; experience fallacious, and judgment difficult."

\section{THE ARREST OF PULMONARY TUBERCULOSIS. ${ }^{1}$}

BY J. KINGSTON FOWLER, M.A., M.D.CANTAB., F.R.C.P. LOND.,

PHYSICIAN TO THE MIDDLESEX HOSPITAT AND LECTURER ON MEDICINH

IN THE MEDICAL SCHOOL; PHYSICIAN TO THE HOSPITAL FO

CONSUMPTION AND DISEASHS OF THE CHEST, BROMPTON.

IT is unnecessary nowadays to insist that tuberculous disease of the lungs frequently undergoes arrest; the fact is admitted by all and is the common knowledge of the reader of any up-to-date magazine. It was not, however, always so, for I can recall the time when such an event was believed even by well-informed members of the profession to be only

\footnotetext{
1 A lecture delivered at the Brompton Hospital on June 7th, 1899.

the most rare occurrence and when one was not infrequently asked, Do you ever really cure a case of consumption at Brompton? To this question I bave generally replied in the words of Laennec, "The cure of tuberculous phthisis is possible to nature ; it is certainly not yet so to medicine." In medicine, as in other sciences, it is well from time to time to recall the past and to mark the steps by which we have advanced to our present state of knowledge and such a retrospect on the subject of the arrest of pulmonary tuber-. culosis may not be without interest.

Let us consider for a moment the reason for this change of view with regard to the curability of "phthisis." It is certainly not because of the discovery of some drug which will effect this result, for we know of none. It is because truth as to the pathology of the disease has displaced error and because now when we speak of "pulnonary tuberculosis" all men know what we mean, whereas formerly when. one spoke of "phthisis" only the speaker knew (or thought he knew) what he meant. So long as a positive clinical test for the presence of tuberculosis of the lungs was lacking those physicians - and they were neither few nor obscurewho believed in the existence of the conditions variously termed "catarrh of the apex," "congestion of the apex," and " the pre-tuberculous stage of phthisis," regarded every case of the kind in which the symptoms and physical signs disappeared and the patient regained health as an additional proof of the soundness of their belief in the non-specific nature of the affections. They rarely observed the arrest of consumption because if the patient got well it was almost certain that he could not be suffering from consumption! When, however, owing to the researches of Koch it became possible to apply such a test, the falseness of this view was speedily demonstrated, and to-day the discovery of tubercle bacilli in the expectoration is accepted by all as a proof of the presence of tubercle in the lungs.

\section{PATHOLOGICAL RETROSPECT.}

The literature of the subject of tuberculosis from the time of Laennec to the date of Koch's memorable discovery of the tubercle bacillus in 1882 is a history of truth discerned by the unaided senses of a master mind, deduced from accurate and laborious pathological observations, clearly set forth and verified by a wide clinical experience, subsequently becoming obscured owing to the too great reliance of later writers upon the minute anatomical details of morbid struc. tures, as revealed to them by the aid of the microscope, as a test of a tuberculous lesion. Driven from one point to another in their search for some microscopical appearance distinctive of tubercle they were led to deny the influence of a specific virus in the production of the lesions of "phthisis pulmonalis." The description of those lesions given by Laennec is, so far as it goes, striking in its accuracy and marks him as one of the greatest of pathological anatomists. No less accurate were his views upon such questions as the rôle of ordinary inflammation in the pathology of tubercle; of the influence of "a neglected cold" in the etiology of phthisis ; and the relation of pleurisy to tuberculosis of the lungs-questions which long after his time continued to perplex the minds of pathologists and to which, indeed, we have only lately been in a position to give something approaching to a final answer.

At the time when I began the study of medicine the majority of my teachers were under the baneful influence of the views of Niemeyer, who took credit for having gradually emancipated himself from the teachings of Laennec. What Niemeyer's views were will be readily seen from the following brief extracts from his work. "We must emphatically express our dissent from the theory that caseous infiltration of the lung, with its concomitant formation of vomicæ, has its source in a primary inflammation of a peculiar nature which is distinguishable from the varieties of pneumonia." "The consolidation and destruction of the lungs which form the anatomical basis for consumption are usually the products of inflammatory action and the greater the quantity of cellular elements collected in the vesicles and the longer the duration of the inflammation, so much the more readily will pneumonia lead to consumption ......" And again "we have no hesitation in saying that the greatest danger for the majority of consumptives is that they are apt to become tuberculous." Truly Laennec is revenged upon those who rejected his gospel

Students in my day were duly instructed as to the varieties of "phthisis," and I can still recall my hopeless attempts 
to untterentiate " tuperculous phohlsls" from " vatarraal phthisis" and "pneumonic phthisis," whether acute or chronic, confluent or disseminated, from the tuberculous or tuberculo-pneumonic variety. The relation of fibroid phthisis to chronic phthisis was a special puzzle and the supposed existence as separate species of the disease of bronchiectatic, diabetic, miner's, collier's, knife-grinder's, and syphilitic phthisis completed one's state of bewilderment. We were taught that acute tuberculosis of the lungs was a different affection altogether from phthisis and yet in the post-mortem room it appeared to be not infrequently associated with it. As my pathological experience increased I was led to range myself with those who held Laennec's view of the "unity of phthisis," and it is some consolation now to know that one's failure to recognise all these separate varieties of the disease was owing to the fact that they did not exist.

Laennec had no doubt as to the possibility of phthisis undergoing arrest in the stage of cavity, and he cites several cases of the kind, generally under the heading "Ulcers of the lung cured by their transformation into semi-cartilaginous fistulæ." He was not quite so clear as to the exact mode of production of the pigmented, fibroid, calcareous, and cicatricial lesions frequently found at the apices of the lungs in patients dying from the most varied diseases. He states ${ }^{3}$ : "Nothing is more common than to find on the dissection of those who have died of diseases unconnected with the thoracic organs a small number of tubercles, sometimes rather voluminous, disseminated through a pulmonary tissue otherwise entirely healthy and some of which are already softened or excavated. Nothing having announced in these cases the existence of tubercles we ought, I conceive, to conclude that the same thing must often happen in individuals enjoying excellent health, and then the softening of the tuberculous matter and its evacuation, either by the bronchi or by the action of the absorbents, must be followed by a cicatrix, commonly too small and too similar in texture to the pulmonary tissue itself to render it possible to distinguish it easily, especially at first sight and without that patient exploration which those who undertake to examine whilst influenced by unfavourable prepossessions are unwilling to bestow." It is clear from the foregoing that Laennec believed these to be tuberculous lesions, but I do not think that we can justly credit him with having recognised the fact that a tuberculous lesion may undergo fibroid transformation without the occurrence of softening.

From 1879 to 1886 I kept careful records of all the cases of arrested tuberculosis met with in the post-mortem room of the Middlesex Hospital, during which period I held the post of pathologist to the hospital. These cases were subsequently published in a work entitled "Arrested Pulmonary Tuberculosis" (1891). In 1943 necropsies obsolete tubercle was found in the lungs in 177 cases (Series I.), or 9 per cent. No case was included in this series in which death was due to pulmonary tuberculosis. In a second series of 19 cases it was shown that death occurred from acute tuberculosis of the lungs, similar obsolete lesions being present therein, and that such lesions were the source of infection. In a third series of six cases it was shown that similar lesions may give rise to tuberculosis of organs other than the lungs. The fourth series of 17 cases constituted another link connecting such obsolete lesions with pulmonary tuberculosis, from the fact that they were found in cases fatal from that disease, the appearances met with on post-mortem examination admitting of no other interpretation than that the morbid process had at one time been in a condition of arrest. Finally, it was shown that in some arrested lesions of this kind tubercle bacilli may be found. I also pointed out that in nearly all of the carefully recorded cases of "cured phthisis"-i.e., cases recognised as such during life, observed for many years, fatal from some non-tuberculous affection, and submitted to post-mortem examination-the lesions found in the lungs corresponded in all respects with those described in Series 1. The case of Sir Astley Cooper may be recalled as an illustration of this fact. He left directions that his body was to be examined after death with particular regard to certain points, one of which was "some suspected indications of phthisis in his youth." $\mathrm{He}$ is believed to have had an attack of bæmoptysis for which he bled himself. The result of the examination was that ${ }^{1}$

- Treatise on Mediate Auscultation (Translation), 1846, p. 293. 4 Guy's Hospital Reports, Series I., vol. vi., F. 230 .
- at the superior and posterior part of the right lung there was a small depressea and comewhat contracted surface about the size of a sixpence, a section of which exposed a calcareous mass, very uneven upon its surface and about equal to the size of a small pea. It was placed about three lines distant from the pleura." There is, I imagine, nowadays no one who doubts that these lesions are really evidence of an arrested tuberculosis. It was, however, objected at the time that I published the cases just referred to that although the lesions might be tuberculous the cases had never been clinically examples of "phthisis." This may be at once admitted if by "phthisis" is meant a clinical condition characterised by cough, fever, night sweating, wasting of the body, \&c., but the contention of Laennec and of all who accepted his views has always been that phthisis is tuberculosis of the lungs and nothing else. It is a contention no longer, for it takes two to make a quarrel and there is now no one with whom to contend.

Dr. Sidney Martin ${ }^{\delta}$ has also recorded his experience obtained in the post-mortem room of the Middlesex Hospital in 1890-91. In 445 consecutive necropsies he found obsolete tubercle in the lungs in 42 cases $=9.4$ per cent. Heitler ${ }^{6}$ in the records of 16,562 necropsies performed at the Institute of Pathological Anatomy of Vienna from 1869 to 1897 found 789 cases (= 4 per cent.) in which obsolete tubercle was present in the lungs. It will be seen that Dr. Sidney Martin's results and my own almost exactly correspond, whereas the proportion in Heitler's series is much smaller. I am disposed to attribute this to the fact that amongst the bodies examined at the Middlesex Hospital there is a far larger proportion of cases of cancer, owing to the existence of a special cancer department there wherein the patients, in the language of the Founder, "remain until relieved by art or released by death." I have shown that evidence of the arrest of a previous tuberculosis is more common when death occurs from cancer than when it occurs from any other disease. Other observers have found evidence of arrested tuberculosis in a far larger percentage of cases than those above stated, 23 per cent., 38 per cent., and even 60 per cent. being recorded. It is difficult to account for this discrepancy and time does not permit me to discuss the question on this occasion.

\section{PROCESS OF ARREST.}

The exact process by which the arrest of the disease is effected is a matter of much moment to the patient, for apon it may depend his prospects of future health. Three chief varieties of obsolete lesions may be recognised. 1. Pigmented tubercles which have undergone fibrosis may be seen upon the margins of areas of fibroid induration around which there is much puckering and scarring and within which small caseous or caseo-calcareous nudules are often present. This is the most common form of arrested lesion and is fortunately the one which is least likely to be a source of subsequent re-infection, as although a few tubercle bacilli may be found in the centres of the small caseous nodules the organisms are probably no longer active. Dr. Sidney Martin was unable to reproduce the disease by inoculation with such material. Tubercle bacilli can rarely if ever be found on microscopical examination of sections through the fibroid structures which constitute the greater part of lesions of this kind. 2. A caseous mass of considerable size-e.g., of that of an olive or a small walnut-may become surrounded by a fibrous capsule. This is a condition fraught with great possibilities of danger. I have reported a case in which such a mass had probably been present for 40 years, but owing to the destruction of the capsule surrounding it the caseous contents were discharged into a bronchus and death from acute tuberculosis of the lungs occurred in 28 days. 3. Arrest may take place after the formation of a cavity. This, although certainly not so favourable a condition as that first described, is nevertheless not incompatible with long life. I described in 1892 the case of a woman who had a cavity at the apex of the left lung which was then of 47 years' standing. She is still alive and well.

I think that as a general rule when arrest takes place in the stage of cavity the patient ultimately dies from some pulmonary disease. The liability to the formation of an aneurysm of the pulmonary artery must also be remembered in forming a prognosis in such a case. 
CONDITIONS INDUCING ARREST

No attempt was made in the cases to which reference has just been made to determine the conditions which had led to the arrest of the disease; the observations were pathological only and it is unlikely that the medical histories would have repaid detailed examination. In the great majority there would certainly have been nothing to suggest the presence of a tuberculous lesion of the lungs. In my experience records, whether pathological or clinical, to be accepted as evidence on any particular point must be made with a definite relation to that point, and the medical history in these cases had not been taken with especial reference to the possible presence of an arrested tuberculous lesion in the lungs. It is probable that in most of the cases infection occurred at some period when the resisting power to disease had been temporurily lowered by unfavourable circumstances, and that this period had been followed by one of increased vitality which prevented further extension of the disease. All who have had the experience which is to be gained by a long attendance in the out-patient department of this hospital must have observed many cases in which the disease has ultimately undergone arrest, although perbaps there seemed at first little probability of such a termination. Arrest is not impossible even to the dweller in a London slum and it may be unattainable to one who has all that wealth can purchase.

Tuberculosis of the lungs is a disease the treatment of which has always excited to a marked degree the interest both of the medical profession and the public; this, however, has not always proved of unmixed advantage, as was amply demonstrated during the tuberculin craze in 1890 . As I have ventured to remark elsewhere, ${ }^{7}$ "the great interest excited throughout the world by Koch's announcement is still fresh in our memories, the lamentable lack of judgment, of self-control, and of those critical faculties which should characterise the members of a scientific profession displayed by many on that occasion may serve as a warning for the future." The medical profession and the public are now passing through a similar though less acute phase of excitement with regard to the "open-air" method of treatment and it may be useful to recall these words of warning ere extravagant hopes are formed of the results likely to be obtained. This I say not from any lack of confidence in the method, for on the contrary I hold that its value has been conclusively proved, but because I fear that, in some quarters at any rate, there are signs of a failure to appreciate the long period of treatment required, even after arrest has been obtained, to consolidate the lesions and to render them capable of withstanding the strain which the ordinary work of life entails.

\section{ARREST, How Procured.}

The past 25 years have witnessed the trial of many reputed remedies for "phthisis," nearly all of them lauded either as specifics or as having been observed to produce a marked effect upon the course of the disease. Approval of these methods of treatment has in many cases not been limited to their discoverers. I have sometimes thought that it would be an advantage if the publication of therapeutic conclusions were restricted to such members of the profession as had proved themselves to possess a capacity for accurate clinical observation. Had it been so we should certainly have been spared much that has been written with regard to the effect of these remedies upon the course of pulmonary tuberculosis. It is believed to be a matter of extreme difficulty to determine the value of remedies in the treatment of disease. If, however, we may judge from the short period in which, in some cases at any rate, it has been possible to come to a favourable conclusion-e.g., the use of salicin and its compounds in the treatment of acute rheumatism, of thyroid extract in myxcedema, and of the diphtheria antitoxin-it is permissible to doubt whether in general this is not due to the absence of any value in the remedy and not to the inherent difficulty in the observation.

As to the methods most likely to bring about arrest of the disease I have ever held but one opinion which I may quote from the work on "Arrested Pulmonary Tuberculosis," to which $I$ have already referred ${ }^{8}$ : "It is not to remedies which effect the elimination of tubercular deposits that we must louk forward with hope in our battle with pulmonary tubercc.osis, but rather to such as increase the resisting porer of the individual and enable his tissues to stop the progress of the disease. This they are ever striving to do, even when the destructive process is most acute, and it is only necessary that the local or constitutional conditions should turn in their favour for them to commence the construction of the fibrous wall which will turn back the invader." This resisting power is to be augmented by all such measures as in the bealthy tend to maintain health-viz, a quiet life spent chiefly in the open air, plenty of plain food, and exercise suitable to the condition of the individual. We have, indeed, in this country taken long to learn the value of a system of treatment based upon an attempt to develop by every means the resisting power of the body to disease.

Although it is now 45 years since Brehmer enunciated the principles of feeding, rest, graduated exercise, and fresh air, and described the results which he had obtained under his system at Görbersdorf, the " hygienic," "open-air," or "sanatorium" treatment of consumption made little way in this country, chiefly owing, I think, to the belief, which events have proved to be unfounded, that the ordinary English patient would not submit to the restrictions upon his liberty involved in a residence in a sanatorium. It is only lately that the knowledge of the success obtained by Dr. Otto Walther at Nordrach, in Baden, on lines which are a natural development of those laid down by Brehmer, has become general among physicians in this country. My own knowledge of this system and of the success by which in Dr. Walther's hands it is attended is not of yesterday, nor has it been derived from the perusal of magazine articles, but from observation of patients before and after they have undergone treatment there, and I have no hesitation in stating that in my opinion the results observed at Nordrach far surpass any bitherto obtained. It is quite unnecessary for me to describe to you the Nordrach system, as I have already done so at length elsewhere ${ }^{9}$ and much bas since been written about it by others. I shall therefore assume that you are well acquainted with it. The method is being carried out at several recently-opened sanatoria in this country and so far with most encouraging success.

It is, or should be, obvious that the best method of treating any form of disease is that which affords the greatest amount of benefit to the largest number of sufferers ; whether it will cure every case is not the question, although that is the standpoint from which the public, to whom it is now too much the fashion to appeal, is apt to view the matter. The uninformed who may be disposed thus to judge the open-air treatment of tuberculosis will probably find their new-born ardour somewhat damped when they discover, as they certainly will, that it is not possible thus to produce arrest in every case. Whether every patient in any early stage of the affection should be treated in a sanatorium (if it were possible to do so) is a question or which opinions may differ. I certainly consider that a residence, if only for a few months, in such an institution conducted on sound lines is of the greatest value in educating the patient how subsequently to live in a manner most likely to lead to the arrest of his disease, and I believe that such a result is more likely to be thus attained than if he immediately betakes himself to the best climate in the world and lives there without adequate medical supervision. It is infinitely more difficult to enforce the necessary restrictions upon a patient who is living as a free man in a hotel than upon the inmate of a sanatorium. Upon the question of climate I should not like to be misunderstood we have certainly in the past been wont to rely too much upon the influence of climate and to attach too little importance to the necessity for a careful regulation of the details of the patient's life and a dietary abundant even to excess, but to rush to the opposite extreme and to state that "climate has nothing to do with the matter" and that a sanatorium may be placed " in the highlands of Scotland, the lowlands of England, or the bogs of Ireland " is evidence of a state of mind characteristic of the irresponsible enthusiast. No one, surely, will deny that the healthy are influenced by climate. Is it, then, only to the sick that it is a matter of no importance where they dwell? I am glad to know that in selecting a site for the sanatorium which we hope shortly to establish in connexion with the Brompton Hospital we shall not consider that climate is of no importance.

\section{Existing Consumption Hospitals.}

It may occur to some-indeed, it has already been so stated-that if the views here enunciated are sound the existing hospitals for the treatment of consumption and diseases of the chest situated in towns are no longer required 
and that the sooner they are removed into the country the better. A little consideration will show that this is not so and that whatever changes the future may witness it will always be necessary for this hospital to maintain a very considerable number of beds and of course an outpatient department in London. In the first place, a very large number of the patients treated here and in similar institutions are not suffering from tuberculosis. Pleurisy, empyema, bronchitis and other affections of the trachea and larger bronchi, the various forms of disease of the heart and large vessels, mediastinal growths and other varieties of malignant and mycotic disease within the thorax are neither unimportant nor rare affections and sufferers from all of these diseases are constantly under our care. When this hospital has a sanatorium attached to it in the country it will still bo desirable that patients should be under observation for a period before being sent there, as in no other way could the admission of unsuitable cases be prevented, our experience proving that in a very large number of cases the medical certificate entirely fails to disclose the real condition of the patient. The out-patient department of this and similar hospitals will be invaluable for the collection of cases suitable for the treatment in sanatoria, even should such institutions become as numerous as the most ardent supporters of the movement in their favour desire. We can also here commence the education of patients in the advantages of fresh air over the stuffy atmosphere of the rooms in which they too often live; we can show them the necessity for rest in bed when fever is present, a point on which it is most difficult to con. vince patients of the poorer class, and also for scrupulous care in the disposal of the expectoration. To these may be added the great advantage from a disciplinary point of view of a previous stay in hospital before admission to the comparative freedom of life in a sanatorium, a point the importance of which will be readily appreciated by those who have had experience in the management of similar institutions for hospital patients.

To show that it is possible even in the wards of a general hospital by rest and an abundant dietary to produce a very marked effect upon the course of tuberculous disease of the lungs of a very active type $I$ have placed upon the sureen the temperature charts of a case recently under my care in the Middlesex Hospital. They extend from the date of the patient's admission on Nov. 25th, 1898, to April 6th, 1899, when he left for the convalescent home at Clacton-on-Sea, and from April 28th, on his return, to May 6th. With the exception of one fortnight the temperature was taken every four hours and from Jan. 9th it was taken for a period of three minutes in the mouth and in the rectum simultaneously.

The patient was a man, aged 22 years. There was no family history of tuberculosis. Six weeks before admission, after rowing, he was suddenly seized with a rigor. For the fortnight following, although feeling ill, he went to his business as usual. On Oct. 28th he took to bed under medical advice. On Nov. 1st he had an attack of pleurisy on the left side. $A$ week later he got up and was about for three days. He then had "influenza" and returned to bed with a high temperature and pains in the back, head, and legs. This lasted until Nov. 16th, when he was attacked with "pneumonia," the symptoms being cough and expectoration with some dyspnoea. $\mathrm{He}$ then had a slight hæmoptysis. Almost throughout the illness thus variously named he had been suffering from night sweats and had emaciated considerably. The patient's weight on Oct. 13th, immediately before the onset of his illness, was $9 \mathrm{st} .2 \mathrm{lb}$. The patient was a man of poor physique and the examination of the chest showed the presence of fine crackling râles in the left supra-spinous fossa and also at the apex of the lower lobe on that side. There was a pleural friction sound in the left axilla. The temperature was $103.2^{\circ} \mathrm{F}$. and the pulse
was 102. The sputa contained tubercle bacilli. On Dec. 8 th the patient was placed on the following diet. At 5 A.M. balf

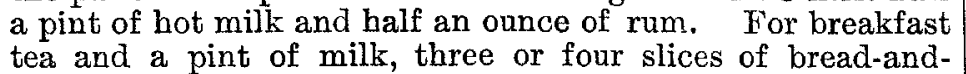
butter, and one egg. At 9 A.M. a pint of milk. For luncheon half a pint of soup or beef tea and a piece of bread. For dinner a chop, potatoes, and greens, milkpudding, a pint of milk, and a piece of bread. For tea three or four slices of bread-and-butter and one egg. For supper half a pint of soup or beef tea and a piece of bread. At 8 P.M. a pint of milk.

The activity of the morbid process in this case is to some extent indicated by the fact that there was continuous pyrexia for 26 days, the temperature first touching $98_{\tilde{5}}^{\circ}$ on Dec. 22nd. For the first fortnight of his stay in hospital the temperature (taken in the mouth) ranged between $100^{\circ}$ in the morning and $102^{\circ}$ in the evening, during the second fortnight between $99^{\circ}$ in the morning and $101^{\circ}$ in the evening, and during the last week of December between $999^{\circ}$ and $98 \frac{2}{5}^{\circ}$. From Jan. 9th up to March 1st, 1899, when the patient suffered from a typical attack of influenza, several cases

Chart' I.

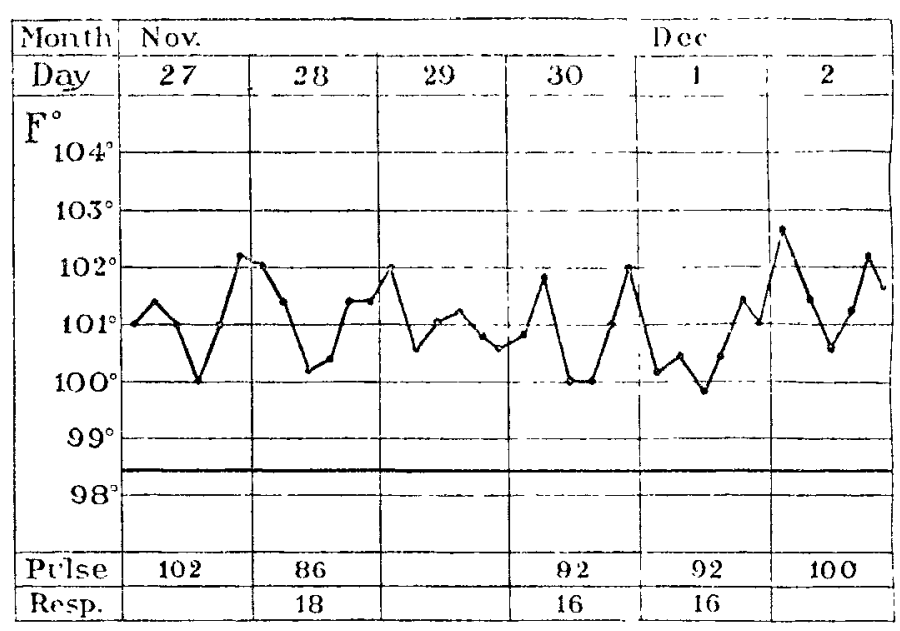

Oral temperature during first week of treatment.

of which disease were in the ward at the time, the fever was of a mild remittent type with a gradual tendency to decline. After the attack of influenza, which was accompanied by high fever, the temperature resumed its previous type but with a rather wider range. The temperature for the first week and last week of treatment are here given (Charts 1 and 2). The physical signs indicated at first an extension CHATRT 2.

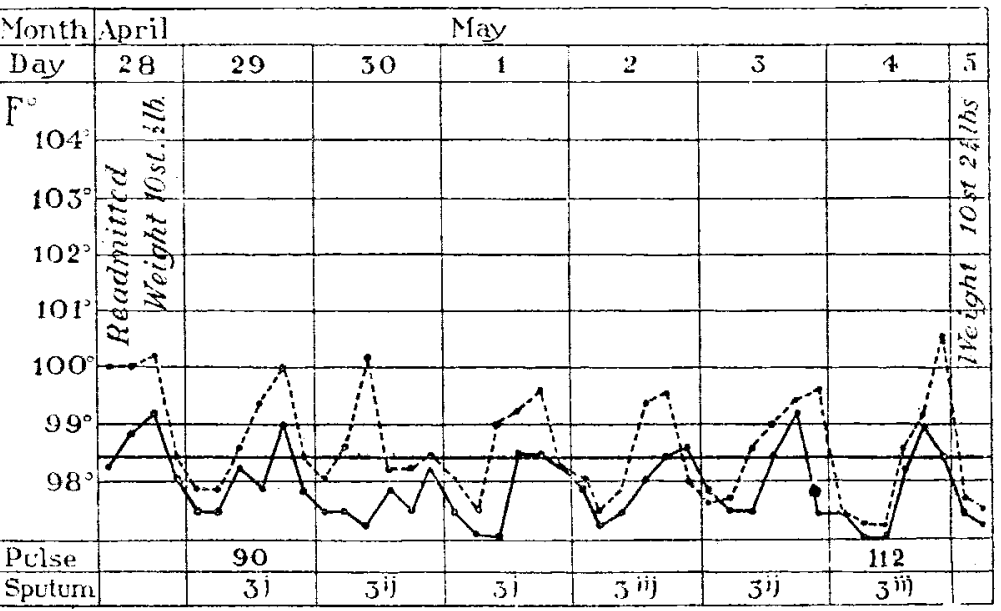

Oral and reetal (dotted line) temperatures during last week of treatment.

of the lesions in the left upper and lower lobes, the crackling râles becoming more numerous and reaching for a greater distance along the interlobar septum. Subsequently, as the temperature fell they were less distinct, except after the attack of influenza. A few râles were still present at the time of the patient's final discharge. The cough was troublesome throughout. The expectoration varied in amount and there were about two drachms daily of thick, yellow, muco-purulent sputum, containing abundance of tubercle bacilli when the patient left the hospital. The following table shows the state of the body-weight at various periods; it is unfortunate that it was not taken on his admission.

Oct. 13th

(Dec. 8th, extra full diet.)

$\begin{array}{llllll}\text { Dec. } 29 t h & \ldots & \ldots & \ldots & \ldots\end{array}$

Jan. 5 th

Jan. 12th

Jan. 19th

Jan. 26th

Fet. 2nd

Feb. 9th st. lb.

92

$7 \quad 7 \frac{1}{2}$

$710 \frac{1}{2}$

713

83

86

$810 \frac{1}{4}$

90 st. Ib.

$\begin{array}{lllllll}\text { Feb. 16th } & \ldots & \ldots & \ldots & \ldots & 9 & 3\end{array}$

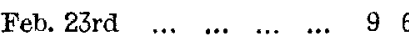

(March 1st, attack of infuenza.)

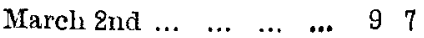

$\begin{array}{lllllll}\text { March } 9 \text { th } & \ldots & \ldots & \ldots & \ldots & 9 & 7\end{array}$

$\begin{array}{llllll}\text { March 16th ... } & \ldots & \ldots & \ldots & 9 & 6 \frac{1}{2}\end{array}$

$\begin{array}{llllll}\text { March } 23 r d \ldots & \ldots & \ldots & \ldots & 9 & 8\end{array}$

$\begin{array}{lllllll}\text { April 28th } & \ldots & \ldots & \ldots & \ldots & 10 & 0\end{array}$

$\begin{array}{lllllll}\text { May } 5 \text { th } & \ldots & \ldots & \ldots & \ldots & 10 & 2 \text { is }\end{array}$ 
CHART 3.

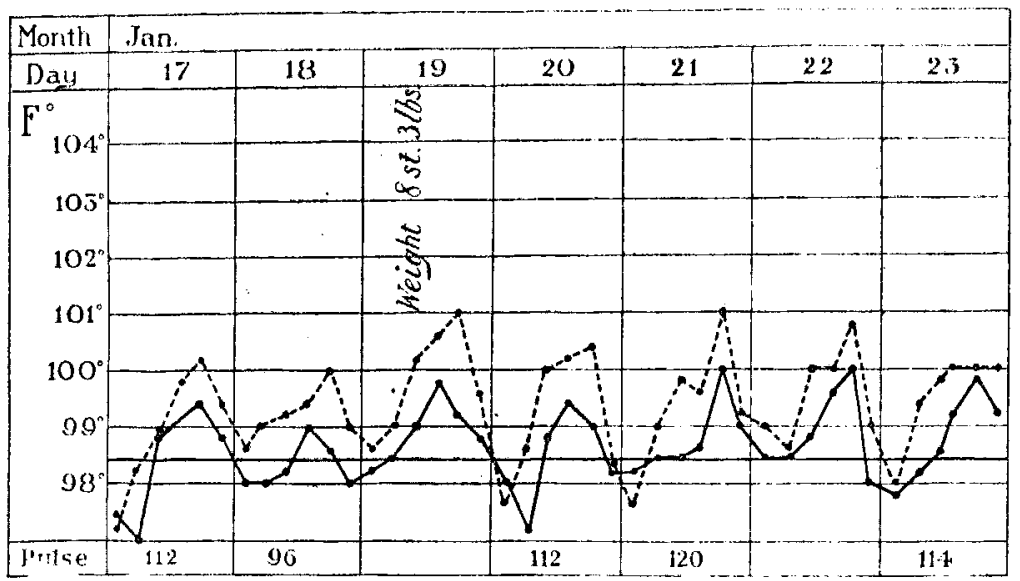

Chart illustrating the difference between the temperature in the mouth and that in the rectum (dotted line).

The failure to maintain the gradual increase in weight during the month of March was clearly due to the attack of influenza.

There are two points in this case to which $I$ wish to direct attention. One is the remarkable gain in weight probably from about $7 \mathrm{st}$. (certainly from $7 \mathrm{st}$. $7 \frac{1}{2} \mathrm{lb}$.) to 10 st. $2 \frac{1}{4} \mathrm{lb}$. This occurred notwithstanding the fact that the disease was not arrested, as is shown by the presence of cough and expectoration and the discovery of numerous tabercle bacilli in the expectoration when the patient left the hospital. This very considerable gain in weight I attribute to the large quantity of food which the patient took and assimilated. That a patient may gain in weight and yet the disease may not be arrested is no new observation, but with an ordinary hospital diet it is, in my experience, a rare event for a patient to gain 3 st. in weight without the disease undergoing arrest. What I observed in this case accords with my experience of others treated on similar lines (rest and hyper-alimentation), and I believe that the larger the quantity of food administered the less is the significance to be attached to a gain in weight as evidence of the arrest of the disease. I do not say that a gain in weight is not of importance. On the contrary, it is a fact of the greatest moment, for without it the progress of the disease is almost certain, but it is not by itself, even when remarkable in amount, a proof of arrest, when the quantity of food taken has been unusually larce. I so frequently observe reference to the increase in weight in patients submitted to this method of treatment that I think it desirable to draw attention to the fact just stated.

The second point is the difference between the oral and the rectal temperatures (Chart 3). You are doubtless aware that at Nordrach the patients take their own temperatures in the rectum four times daily, and so far as I have been able to learn they do so without expressing any particular objection. The necessity for such a proceeding, which for obvious reasons does not appear at first sight to commend itself, has not hitherto been recognised in this country. The oral temperatures in the evening were from $0.5^{\circ}$ to $1^{\circ}$ or even $2^{\circ} \mathrm{F}$. lower than the rectal. The oral temperatures in the morning were usually slightly above the rectal but sometimes one-fifth of a degree below. There was thus a far greater difference between the temperature in the mouth and that in the rectum at the higher than at the lower level.

The important question whether the patient is to remain at rest or to take exercise and the amount of exercise to be taken is to be decided by the presence or absence of pyrexia. It is therefore of great moment to know the real temperature of the body, not merely that of the mouth. Now it is clear that the difference between the temperature in the mouth and in the rectum may be as much as one degree or one and a half, or even two degrees. It has, I believe, been shown that in order to invariably obtain the true temperature in the mouth it is necessary to close the lips for 20 minutes before inserting the thermometer. If there were a constant difference between the oral and the rectal temperature it is obvious that it would only be necessary to know this and to take it into consicleration in reading the temperature as taken in the mouth, but, as these charts prove, the difference is not constant but extremely variable. I am therefore led to the conclusion that the only trustworthy method of ascertaining the temperature of the body is to take it in the rectum.

IIospitals for consumption have in the past conferred incalculable benefits on sufferers from tuberculosis, but owing to the necessary limitation of the period of treatment it has not been possible here to set before ourselves as an objective in all suitable cases the complete arrest of the disease, and had we possessed a sign-board we should, I fear, have been compelled to imitate the humble craftsman and imprint upon it the words "Repairs neatly executed." Let us hope that in the future by greatly extending the period of treatment it may be possible in a much larger proportion of cases to secure such complete arrest. Herein, indeed, lies the difficulty in dealing with hospital patients, especially such as have families or relatives dependent upon them for support, as they cannot in most cases afford the time necessary to secure permanence of the reparative changes taking place in the lungs. How long a period of complete rest is generally necessary to effect this must have been appreciated by all who have had an extended experience in the treatment of such cases.

Clarges-street, Mayfair, W.

\section{THE PREVENTION OF SYPHILIS. ${ }^{1}$ \\ BY FRANCIS H. WELCH, F.R.C.S. ENG., SURGEON-COLONEL (RETIRED), MEDICAL STAFF.}

IN entering upon the question of the prevention of syphilis there are two features which require full recognition, as upon them this problem rests, one etiological and pathological, physical-the cause, its multiplication in the frame, and mode of transfer from individual to individual ; the other socio-moral, ethical-that phase of our civilisation, promiscuous intercourse, by which the cause is mainly spread in the community. It is the relationship of the latter to the former as determining the outcome-prevalence of disease-which compels us to consider the question as a whole and not merely from a hygienic standpoint when deciding on the action to be taken under our present civilisation and polity.

The cause, which everywhere (and the same pertains in time from the earliest recognition of the disease) demonstrates the presence of syphilis through similar manifestations is, we infer, an organic entity - a microorganism-not yet identified. While capable of transfer to certain animals (though this is denied by some) it is practically a human malady which is communicated through contact (acquired) or through parentage (inherited). $A_{s}$ a rule it enters the body by surface inoculation, and in a lesser ratio by the blood or semen. In the first case it sets up active changes at the site and in the contiguous lymph glands suggestive of attempted preclusion and localisation of the virus, yet followed for the major part by a true systemic infection; in the second case it is directly transmitted to the system of the individual or embryo through these media. During the primary and secondary periods the virus is capable of being inoculated, and during the latter period it is capable of being transferred with the blood or semen, but how far beyond the period of active changes it can be transferred to the embryo seems an. undetermined point.

Like disease in general the origin of this special malady is obscure. Whether it is primarily a pathogenic germ apart from the human frame, or is primarily innocent yet pathogenically evolved under a favourable human environment, or is derived from normal elements adversely modified; whether, again, it arose in one or several sections of the human race; or whether it is capable of a spontaneous recrudescence in the future if conditions permit-these are not merely points of academic interest but they have an important bearing on the eradication of the cause. For present practical purposes we know of it only as arising from pre-existent disease and as transferred throughout the world at large in the selfsame methods, and while

1 A paper read before the British Medical Association, August 3rd, 1899. 